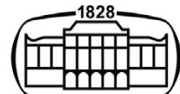

AKADÉMIAI KIADÓ

\section{Acta Veterinaria}

Hungarica

$68(2020) 2,212-220$

DOl:

$10.1556 / 004.2020 .00033$

(c) 2020 The Author(s)

\section{ORIGINAL ARTICLE}

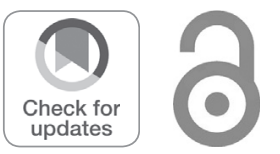

\title{
Development of a surgical technique for long- term catheterisation of bovine fetuses
}

OTTÓ SZENCI ${ }^{1 *}$ (D), KAMAL TOUATI ${ }^{2}$, NOELITA MELO DE SOUSA $^{3}$, JEAN-LUC HORNICK ${ }^{4}$, GIJSBERT CORNELIS VAN DER WEYDEN ${ }^{5}$, MARCEL ANTONIE MARIE TAVERNE ${ }^{5}$ and JEAN-FRANÇOIS BECKERS ${ }^{3}$

\footnotetext{
${ }^{1}$ University of Veterinary Medicine Budapest, Department of Obstetrics and Food Animal Medicine Clinic and MTA-SZIE Large Animal Clinical Research Group, Üllö, H-2225, Hungary

${ }^{2}$ Surgery of Large Animals, Faculty of Veterinary Medicine, University of Liège (ULg), Liège, Belgium

${ }^{3}$ Physiology of Reproduction, Faculty of Veterinary Medicine, University of Liège (ULg), Liège, Belgium

${ }^{4}$ Nutrition of Large Animals, Faculty of Veterinary Medicine, University of Liège (ULg), Liège, Belgium

${ }^{5}$ Department of Farm Animal Health, Foetal and Perinatal Biology, Faculty of Veterinary Medicine, Utrecht University, Utrecht, The Netherlands
}

Received: November 29, 2019 • Accepted: May 08, 2020

Published online: August 28, 2020

\begin{abstract}
The aim of this study was to further develop and extensively describe a surgical technique in order to realise long-term fetal blood sampling in the bovine species. Eleven Holstein-Friesian 6- to 8-month pregnant cows (4-10 years old) were used for this study. Gestational age on the day of surgery varied from approximately 180 days $(n=1)$ to 240 days (minimum: 232 days, maximum 252 days; $n=10$ ). The fetal medial tarsal artery was catheterised in pregnant cows with a polyvinyl catheter in dorsal recumbency under general anaesthesia. Although 5 out of 11 operations (45.5\%) performed between 232 and 252 days of gestation were lost due to different causes mainly associated with peritonitis and septicaemia, the mean interval between operations and calvings was 42.5 days (between 27 and 95 days). It is important to emphasise that a well-trained surgical team is needed for bovine fetal cannulation in order to be able to decrease the risk factors during the operations. Due to the fact that after 5 unsuccessful cases none of the pregnancies were lost, this skill can be reached, and our technique can enable bovine fetal blood sampling for long-term endocrinological and physiological investigations before and during parturition.
\end{abstract}

\section{KEYWORDS}

dairy cow, fetal surgery, anaesthesia, parturition

\section{INTRODUCTION}

Fetal catheterisation is an efficient tool allowing longitudinal in vivo studies on endocrinology, oxygenation and acid-base balance of fetuses. A major advance was made when the method for insertion and maintenance of catheters in umbilical and uterine vessels under chronic conditions was introduced for sheep and goats by Meschia et al. (1965). Since then the technique has been widely used for various studies on placental transfer in conscious sheep (Comline and Silver, 1970, 1972) and in other large domestic animals such as the cow (Comline et al., 1974), mare (Comline et al., 1975) and pig (Comline and Silver, 1974; Randall, 1977). At the same time, no detailed description of the surgical techniques was given, which may explain why the subsequent catheter implantations were not successful in each case (Sangild et al., 2000; Aoki et al., 2002; Schmidt et al., 2004). 
The aim of this study was to further develop and extensively describe a surgical technique in order to realise long-term fetal blood sampling in the bovine species. The catheterisation of fetuses was based on the technique described previously with some modification (Taverne et al., 1988; Sangild et al., 2000).

\section{MATERIALS AND METHODS}

\section{Animals}

Eleven Holstein-Friesian 6- to 8-month pregnant cows (410 years old) were used for this study. The experimental protocol was approved by the ULg Ethics Committee (Dossier number 216). Before bringing the pregnant animals to the clinic (Faculty of Veterinary Medicine, Sart-Tilman, Belgium), they were tested for tuberculosis, brucellosis, leucosis, IBR and BVD, and all animals were negative. Gestational age on the day of surgery varied from approximately 180 days $(n=1)$ to 240 days (minimum: 232 days, maximum 252 days; $n=10$ ). Hay and $4 \mathrm{~kg}$ of overpressed sugar beet pulp (50\%) and alfalfa (50\%), as well as $100 \mathrm{~g}$ of mineral-vitamin supplement (15/15 Vitamex, Cafos, Brenntag, Belgium) were given to the animals. Water was available ad libitum.

During the experiment, a complete general clinical examination of the cows was performed once or twice daily. This consisted of measuring rectal temperature, heart and respiratory rate, cardiac, pulmonary and abdominal auscultations (intestines and rumen contractions), examinations of mucosal condition (buccal and/or ocular), as well as appetite and faeces.

\section{Pre-surgical care}

Two days before operation the animal was completely cleaned and washed. Food and water were withhold for 24 and $12 \mathrm{~h}$ before surgery, respectively. Antibiotics (Depocilline ${ }^{\circledR}$ MSD, Belgium, at a dose of $7.2 \mathrm{mg} / \mathrm{kg}$ ) and (Depomycin $^{\circledR}, \mathrm{MSD}$, Belgium; a combination of penicillin and streptomycin at a dose of $8.0 \mathrm{mg}$ penicillin/ $\mathrm{kg}$ and $8 \mathrm{mg}$ of streptomycin $/ \mathrm{kg}$ i.m.) were administered. Moreover, a selenium/vitamin E injection (Myogaster ${ }^{\circledR}$, VMD, Arendonk, Belgium) at a dose of $40 \mathrm{~mL}$ per cow i.m. was given to prevent hyperthermia and myopathy at $6 \mathrm{p} . \mathrm{m}$. on the day before the operation (Day -1).

Four hours before operation (Day 0) a complete clinical examination was performed and the preventive antibiotic treatment of the previous day was repeated with the same doses.

One hour before operation the area $\left(20 \mathrm{~cm}^{2}\right)$ around the lower half of the left flank and the lumbar region was shaved and a jugular catheter $(2.1 \times 80 \mathrm{~mm}$ catheter, Intraflon, Ecouen, France) was placed on the left side. Then, the cow was tranquillised with acepromazine (Combistress ${ }^{\circledR} 2 \%$, Bayer, Leverkusen, Germany) at a dose of $0.1 \mathrm{mg} / \mathrm{kg}$ i.m. After this, the cow was left calm in the darkness.
Before starting the operation the cow was brought into the induction room, where a mixture of $500 \mathrm{~mL}$ glyceryl guaiacolate ether (Eurovet, Heusden-Zolder, Belgium) and 2 g thiopental sodium (Penthotal, Abbot, LLN, Belgium) were given intravenously. During this stage, the animal was lying on its right side on the operating table which was pulled into the operating room. The cow was intubated using a tracheal tube and general anaesthesia was maintained by halothane (Fig. 1). The cow was positioned in dorsal recumbency and the ropes necessary for restraint were placed on the cow's limbs. The extremities of the limbs were wrapped and the hooves were capped with overshoes. The surgical site from the umbilicus to the udder about $40 \mathrm{~cm}$ wide on each side of the midline was shaved and cleaned with isobetadine (Viatris, Bruxelles, Belgique) and then with 50\% ethanol (VWR, Leuven, Belgium) (Fig. 2). After drying the site, it was sprinkled with a powerful antiseptic substance (Sterilium $^{\circledR}$, Bode Chemie, Hamburg, Germany) and then a surgical drape (Barrier ${ }^{\circledR}$ Brand, Gothenburg, Sweden) was

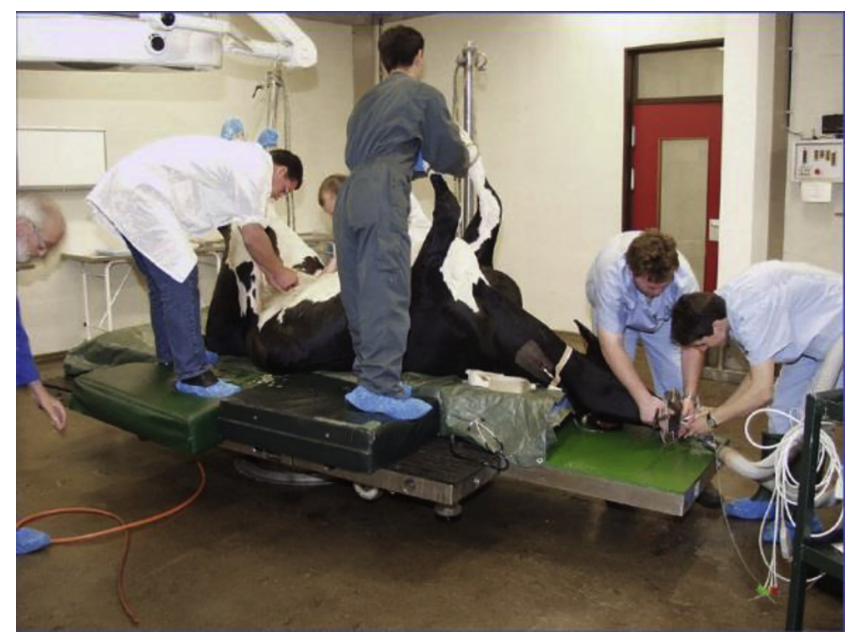

Fig. 1. The cow was positioned in dorsal recumbency under general anaesthesia which was maintained by halothane after intubation

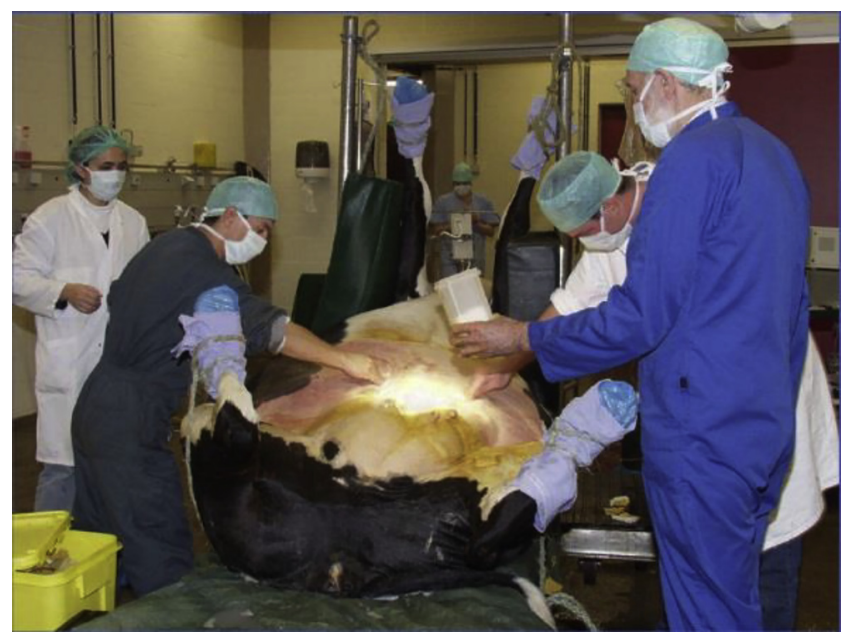

Fig. 2. The surgical area in front of the udder was prepared surgically 
placed on the surgical site. During anaesthesia, approximately 5 L Ringer's lactate (Baxter, Lessines, Belgium) was administered intravenously to protect cardiovascular function. Three tables of surgical instruments were prepared: a first for gathering the instruments used for the cow, a second for the fetus and a third for the catheters.

\section{Surgical technique}

The surgery (Time 0 ) with the incision of the skin over a length of about $20 \mathrm{~cm}$ between the umbilicus and the udder at the midline was started (Fig. 3). At the same time, flunixin meglumine (Finadyne ${ }^{\circledR}$, Schering-Plough, Segre, France) was injected intravenously at a dose of $1.1 \mathrm{mg} / \mathrm{kg}$. After opening the abdominal cavity, the operator manipulated the uterus in the abdomen to correctly position one of the fetal hindlimbs next to the abdominal incision. The fetal hindlimb was carefully exposed so that the foot lay under an

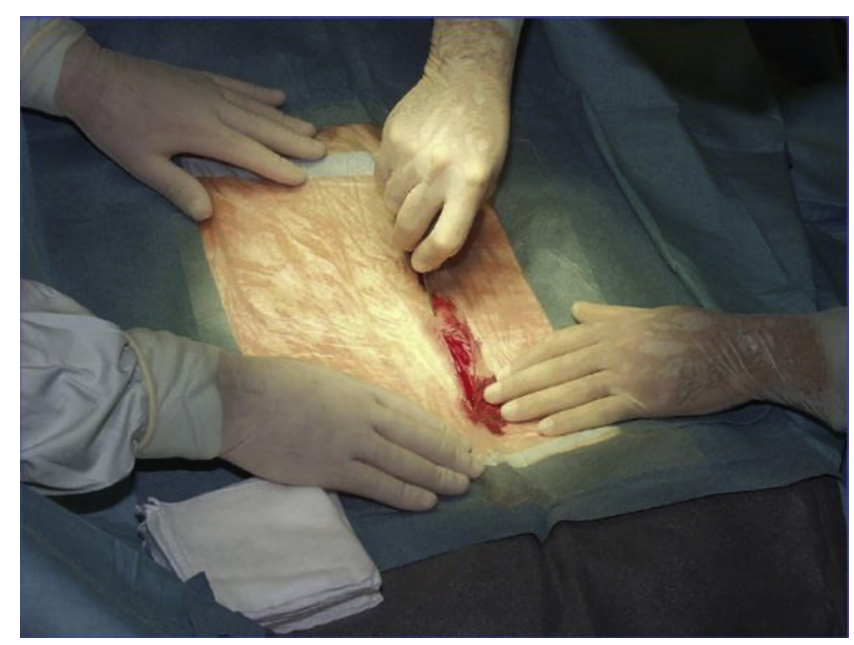

Fig. 3. After covering the linea alba with a surgical drape, the abdominal cavity was opened

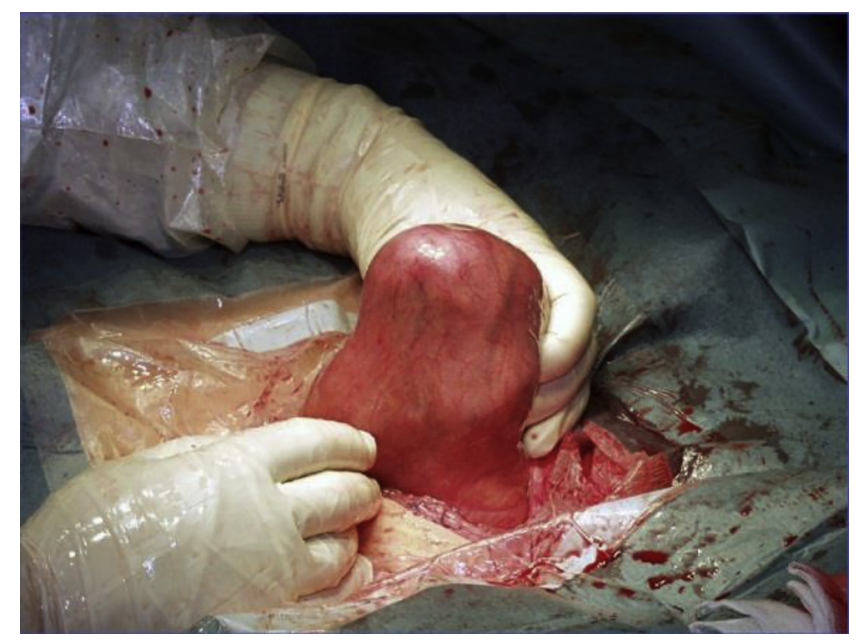

Fig. 4. The fetal hindlimb was identified by intra-abdominal palpation and it was pulled out so that the foot lay in the abdominal incision under an intercotyledonary area of the uterus intercotyledonary area of the uterus in the abdominal incision (Fig. 4). After a careful incision through the uterine wall and fetal membranes (allantois and amnion), the uterine wall and the membranes were progressively fixed together with a Collins forceps after opening (Fig. 5). The fetal limb was withdrawn from the uterus until the anterior surface of the hock joint became easily accessible (Fig. 6). Care was taken to keep the loss of fetal fluids to a minimum. From this stage on, all the exteriorised parts of the limb and the uterus were frequently and abundantly moistened with physiological saline (Kela, Hoogstraten, Belgium).

The skin of the fetal hindlimb was incised on a length of $2 \mathrm{~cm}$ at the medial level of the fold of the hock. The skin lips were kept separated by a wound retractor and the medial tarsal artery was carefully exteriorised (Fig. 7A). After isolation, two threads (Mersuture ${ }^{\circledR}$ 2-0, Johnson \& Johnson, St Stevens Woluwe, Belgium) were placed under the artery (Fig. 7B) in order to be able to catheterise the fetal medial tarsal artery with a polyvinyl catheter $(0.75 \mathrm{~mm}$ I.D. $\times 1.45$ mm O.D.), total length 5-9 m (80 Shores; Medical tubing, Le Bousquet d'Orb, France). For safety reasons, besides the above-given diameter, catheters with multiple diameters (0.81 mm I.D. $\times 1.69 \mathrm{~mm}$ O.D., $1.02 \mathrm{~mm}$ I.D. $\times 1.78 \mathrm{~mm}$ O.D., and $1.27 \mathrm{~mm}$ I.D. $\times 2.29 \mathrm{~mm}$ O.D.) were also prepared.

After opening the artery (Fig. 7C), the insertion of the catheter into the artery was facilitated with a sterile lubricant (Mygliol ${ }^{\circledR}$, Hamburg, Germany). The catheter was connected to a syringe by means of a foam needle (Monoject ${ }^{\circledR}$, Sherwood Medical Company, Missouri, United States) and then filled with heparinised saline solution at a dose of 200 IU heparin (Roche, Bruxelles, Belgium) per millilitre of $0.9 \%$ $\mathrm{NaCl}$ (Kela, Hoogstraten, Belgium).

The catheter was advanced into the artery over a length of $40-50 \mathrm{~cm}$ until the polyvinyl brakes bonded to the catheter so as to lie in the dorsal aorta (Fig. 7D). The proper operation of the catheter was tested by aspirating the blood and, after removing the threads, the catheter was secured to the artery by two simple interrupted sutures (Mersuture ${ }^{\circledR} 2$ 0 ). The skin of the limb was closed with simple interrupted sutures (Mersuture ${ }^{\circledR} 2-0$ ). In addition, the catheter was attached to the skin of the limb by two sutures (Mersuture ${ }^{\circledR}$ 2-0) placed under the polyvinyl brakes to prevent its exit (Fig. 8). The operation of the catheter was again checked by aspiration of the fetal blood. Following closure of the fetal skin, an open-ended polyvinyl amniotic catheter was tied to the leg. The hindlimb was gently returned to the uterus (Fig. 9A). Abundant moistening of the fetal limb-uterus interface with saline solution facilitated sliding of the hindlimb and its placement in the uterus. This was a critical step in surgery during which care had to be taken not to damage the very fragile fetal membranes.

The uterine wound together with the allantoic and amniotic membranes was closed with a continuous suture pattern using Vicryl ${ }^{\circledR}$ (Johnson \& Johnson, St Stevens Woluwe, Belgium) and at the same time the Collins' forceps were removed one by one (Fig. 9B). During this stage, a preventive antibiotic dose ( $1 \mathrm{~g}$ of ampicillin; Ampi-Dry $3 \mathrm{~g}$, 


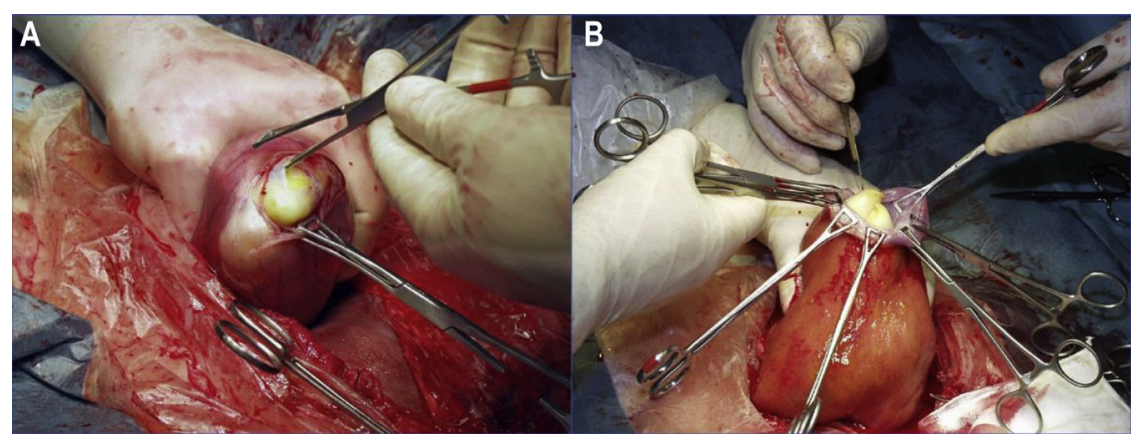

Fig. 5. After careful incision through the uterine wall, the fetal membranes and uterine wall were progressively fixed together with Collins forceps $(A, B)$

Prodivet, Eynatten, Belgium) was administered in the amniotic fluid. After finishing the first simple continuous suture pattern (Fig. 9C), about $40 \mathrm{~cm}$ of the catheter was inserted into the uterus to allow all movements of the fetus without any tension on the catheter. A second continuous Lambert suture pattern $\left(\mathrm{Vicryl}^{\circledR}\right.$ ) was used to close the uterus and finally the uterus was replaced into the abdominal cavity (Fig. 9D).

A long, flexible steel needle (Fig. 10A) was used to tunnel the catheter from the abdominal cavity to the outside of the cow at the lower half of the left flank which was previously prepared surgically (Fig. 10B). Before tunnelling the long needle through the abdominal wall the area was disinfected with Sterilium ${ }^{\circledR}$. When the needle pointed in the shaved area of the left flank, an 1-cm incision was made on the skin at that point for the passage of the needle (Fig. 10C).

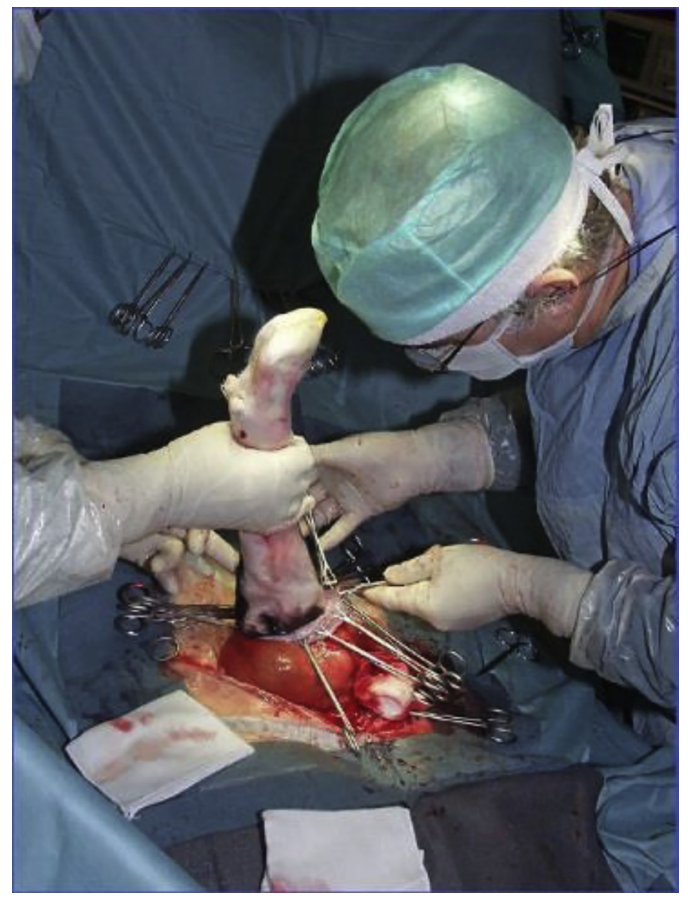

Fig. 6. The fetal limb was withdrawn from the uterus until the anterior surface of the hock joint became easily accessible
The needle was attached to an Anicryl ${ }^{\circledR}$ 3-6 thread (Johnson \& Johnson, St Stevens Woluwe, Belgium) which was attached to a Supramid ${ }^{\circledR}$ (EP6, USP 3, SMI, Hünningen, Belgium) thread of $50 \mathrm{~cm}$ length (Fig. 10A). The other end of this wire was attached to the free end of the catheter, which was previously sealed with Mersuture ${ }^{\circledR}$ 2-0. The whole crossed the left flank. One metre of the catheter was left inside the abdomen to allow all movements of the uterus into the abdominal cavity without any tension on the catheter. Then, the catheter was wrapped in a sterile bag filled with gauze soaked in 50\% ethanol (Fig. 11A) and two interrupted sutures were used to fix it to the skin.

The final stage of surgery (Fig. 11B) was to close the midventral abdominal wall by using a three-layer suture (Anicryl ${ }^{\circledR}$ 3-6) standard procedure (Kersjes et al., 1985). The peritoneum and the linea alba were closed by simple interrupted sutures, then a simple continuous suture closed the subcutis. Finally the skin was sutured with simple interrupted sutures. Thereafter, the surgical drapes were removed and the cow was placed into right lateral recumbency. After this, the catheter was tested again by suction and injection of saline-heparin solution and it was tunnelled subcutaneously along the flank to the most dorsal area of the left sublumbar fossa (Fig. 12). A hypodermic blind needle capped with Luer-lock injection cap was inserted into the external end of the catheter. The catheter was again filled with a sterile heparinised saline solution and put into a plastic bag containing $50 \%$ ethanol solution. The plastic bag was fixed to the skin by two sutures. Two other interrupted sutures were used to close the incision of the skin at the catheter. The abdominal and the left flank wounds were protected by a waterproofing spray (Alluspray, VMD, Arendonk, Belgium). The halothane anaesthesia was stopped just after the fixation of the catheter. When the cow breathed spontaneously, the anaesthesia equipment was disconnected and the animal was taken into the recovery room. The intubation tube was removed and the cow was placed into sternal recumbency. She was left calm for her full awakening until the next morning when she was transferred to her individual pen (Fig. 13). Drinking water was again available and grass hay was given gradually twice a day to return to the normal diet. 

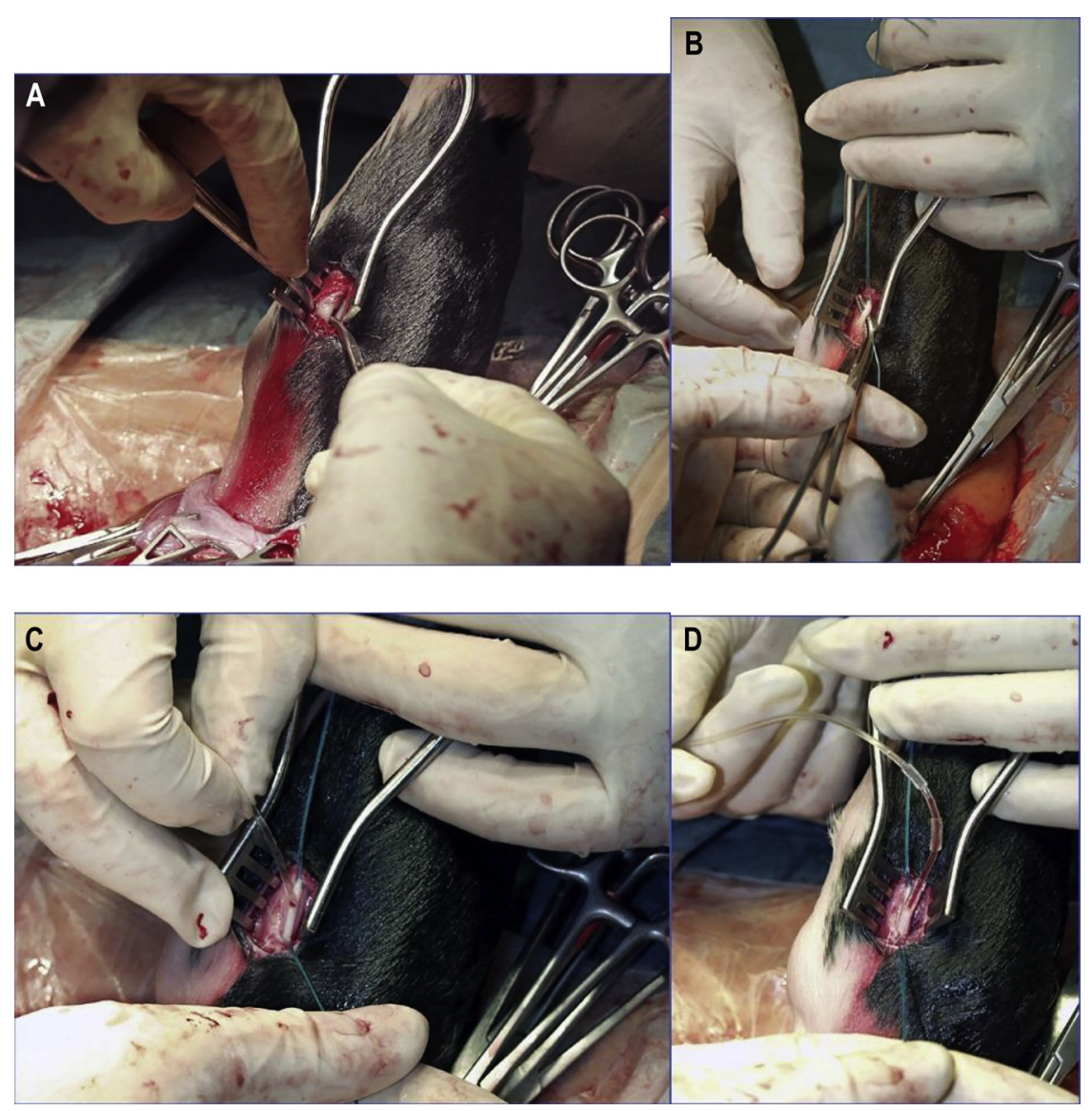

Fig. 7. The fetal medial tarsal artery was prepared cautiously (A), two threads were placed under the artery (B) in order to be able to catheterise the fetal artery with a polyvinyl catheter (C). The catheter was advanced $40-50 \mathrm{~cm}$ so as to lie within the dorsal aorta (D)

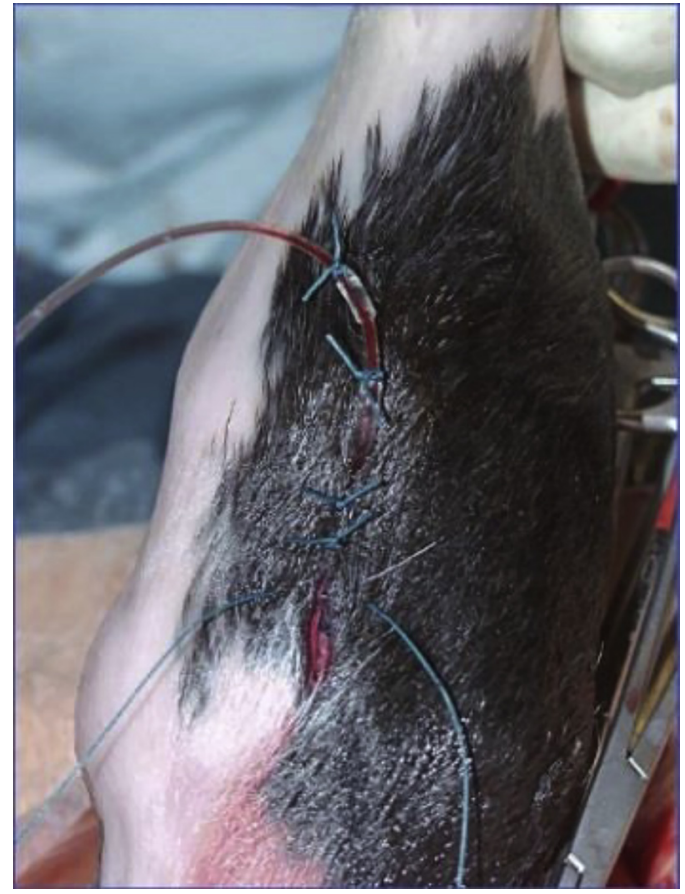

Fig. 8. After closing the fetal wound, the fetal catheter was sutured to the skin
The day after surgery, the catheter was unrolled and its end was placed in a sterile box filled with $50 \%$ ethanol located in a laminar cabinet where the daily sampling of fetal blood took place (Fig. 14). Sampling of fetal blood was begun on the fourth day after cannulation and was performed on a daily basis, usually between 8:00 and 12:00 a.m. until parturition (Fig. 15). Strict aseptic procedures were used at each sampling. In most cases, fetal samples could be withdrawn. However, in some days, blood samples could not be withdrawn probably due to the interference of a blood clot with the catheter or due to the positioning of the fetal hind leg. After each sampling, catheters were flushed and filled with $5 \mathrm{~mL}$ of sterile heparinised solution and the end of the catheter was put back to the small container filled with 50\% ethanol solution.

\section{RESULTS}

The duration of surgery varied from 2 to $8 \mathrm{~h}$ (surgery including a maternal catheter), with a mean of $4 \mathrm{~h} 30 \mathrm{~min}$ for the first 5 cows (Group 1) and $2 \mathrm{~h} 30 \mathrm{~min}$ (without maternal catheter) for the last six cows (Group 2).

In Group 1 (C1-C5), fetal catheters were not functional for more than three consecutive days due to peritonitis 


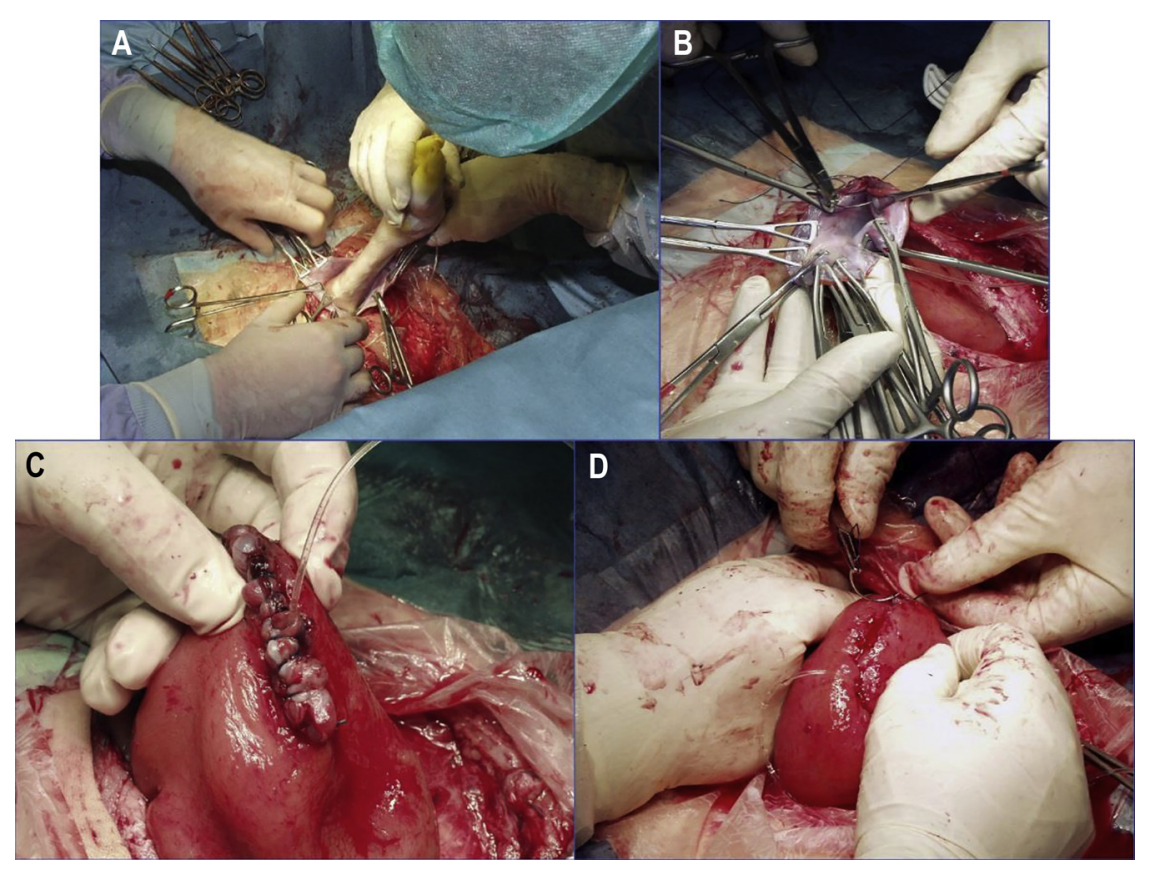

Fig. 9. After carefully returning the fetal leg into the uterus (A), closure of the uterine wound was started with a continuous suture pattern (B) which included all the fetal membranes and the uterine wall (C). A second continuous Lambert suture pattern was used to cover the first row $(\mathrm{D})$

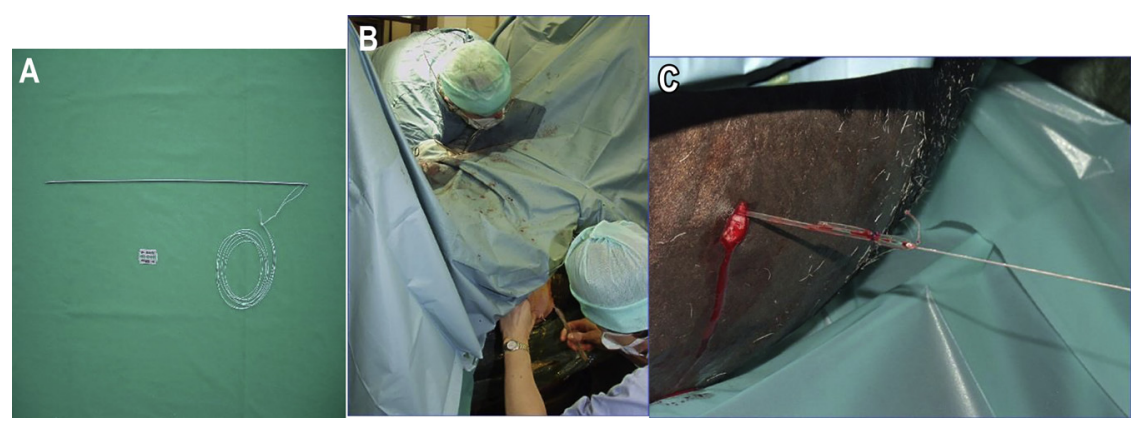

Fig. 10. Before the skin at the medial incision was closed, the catheter was exteriorised through the lateral abdominal wall by a long, flexible steel needle (A) and it was tunnelled subcutaneously along the flank (B). When the needle pointed in the shaved area of the left flank, an 1$\mathrm{cm}$ long incision was made on the skin at that point for the passage of the needle $(\mathrm{C})$

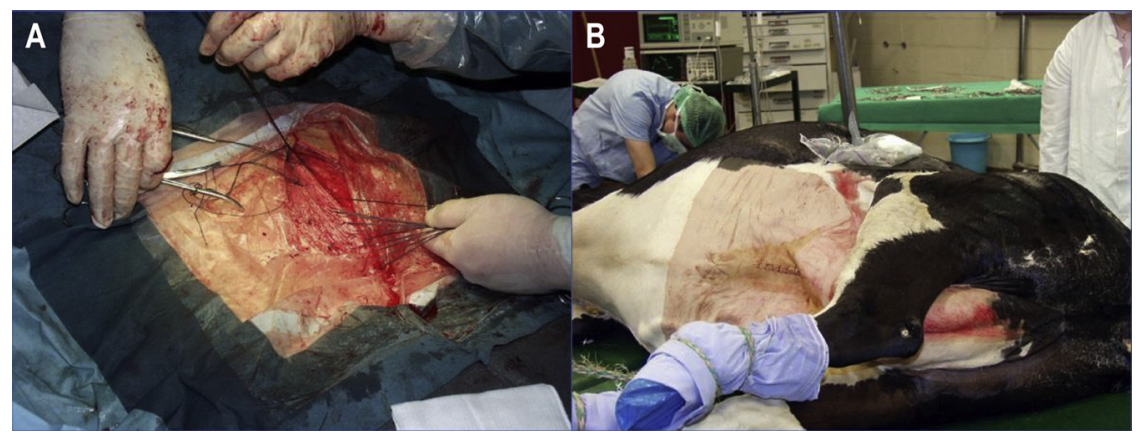

Fig. 11. The catheter was temporarily wrapped and protected within gauze swabs soaked with $50 \%$ ethanol in a sterile plastic bag (A). After turning back to the dorsal position, the abdominal midline incision was closed using simple interrupted sutures (B) 


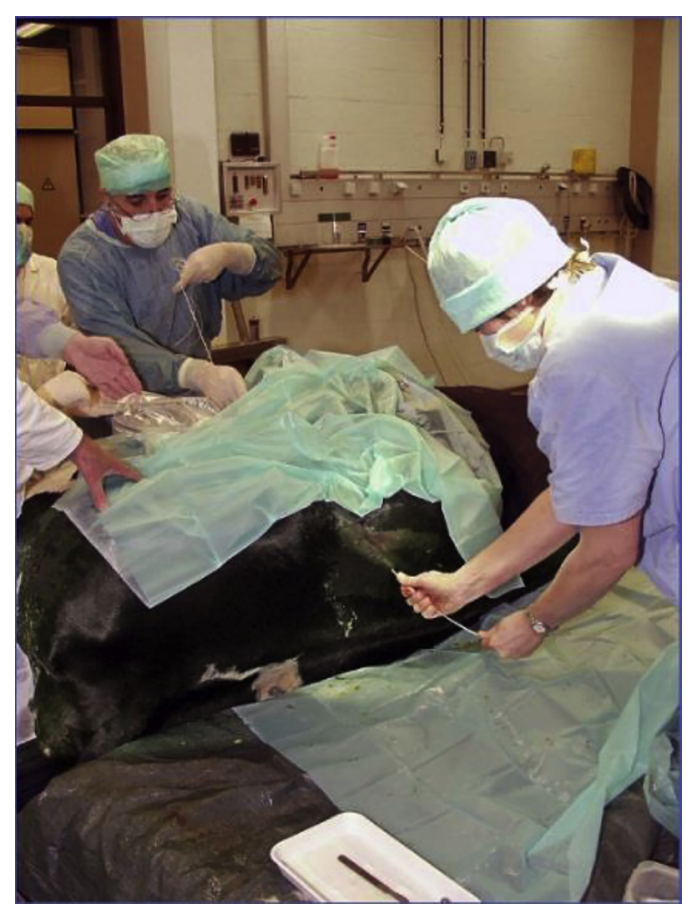

Fig. 12. The catheter was tunnelled subcutaneously along the flank to the most dorsal area of the left sublumbar fossa

followed by abortion (C1, C5), myopathy (C2), premature birth (C3), fetal septicaemia (C4) and intra-catheter coagulation (C5); however, none of the dams were lost.

In Group 2 (C6-C11), cows calved at 270 days (mean) of pregnancy (between 259 and 277 days), which occurred at 42.5 (between 27 and 95) days after surgery (Table 1). One cow, which was operated at about the 6th month of pregnancy, calved at Day 275. Another cow had twin pregnancy but only one of the fetuses was catheterised which did not affect negatively the development of both fetuses. Fetal blood could be taken during a period from 10 to 92 days after the operations, with a mean of 35 days.

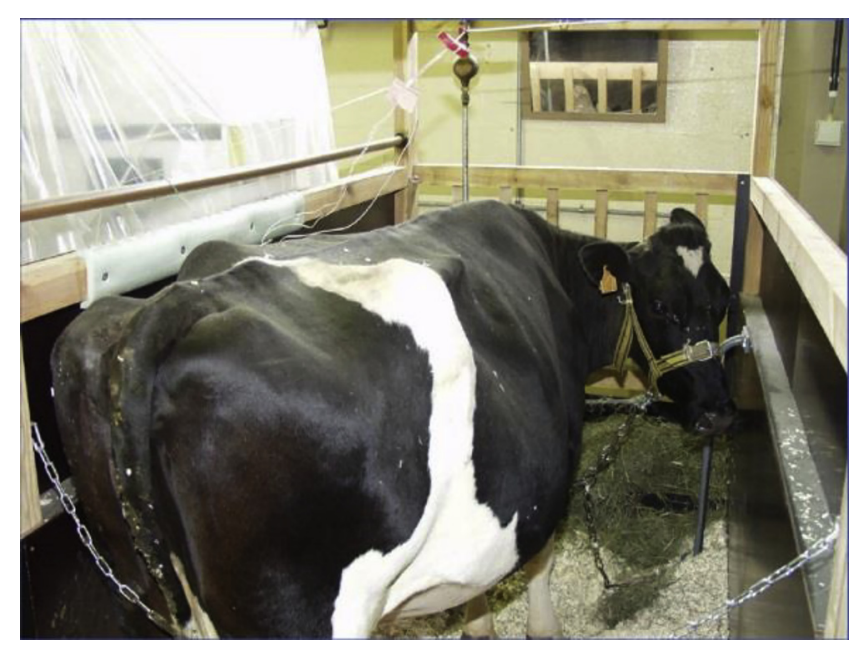

Fig. 13. On the morning following surgery, the cow was placed in an individual pen where she remained until after calving

\section{DISCUSSION}

The mean interval between our successful operations (54.5\%) and calvings was 42.5 days (between 27 and 39 days), while in one case it was 95 days because the operation was performed around Day 180 of gestation (cow C7). To the best of our knowledge, this was one of the longest intervals for cannulated bovine fetuses. Ferrell et al. (1983) reported two successful cases when the cows were operated between 163 and 176 days of gestation and gave birth to healthy calves on Days 281 and 285 of gestation. On the other hand, one of the twin fetuses was also cannulated and this did not cause any disturbance (cow C9).

At the same time, Comline et al. (1974) tried to catheterise the medial or metatarsal vein of the fetal hindlimb through a paramedian incision of the maternal abdominal wall in lateral recumbency between 240 and 260 days of gestation $(n=3)$ but the catheters were dislodged by the movements of the fetuses; therefore, umbilical veins through the cotyledonary branch vessel were selected for cannulation $(n=10)$. The operation needed $1.5-2 \mathrm{~h}$ per Jersey cow. After a mean gestation of $264 \pm 5$ days, each animal gave birth to a healthy calf. In another experiment Comline and Silver (1976) catheterised the umbilical artery and vein in 15 Jersey cows but 3 fetuses died in utero (20\%). The remaining calves were born 7-30 days after the operations after a mean gestation of $267 \pm 4$ days.

The uterine artery and vein, the fetal femoral artery and vein as well as the umbilical vein were cannulated in Hereford cows (4-7 years old) through a mid-ventral laparotomy in lateral recumbency between 163 and $166(n=5)$ days, and 173 and $176(n=11)$ days of gestation, respectively (Ferrell et al., 1983). Two of the 16 cows on which surgery was performed gave birth to live, normal calves at

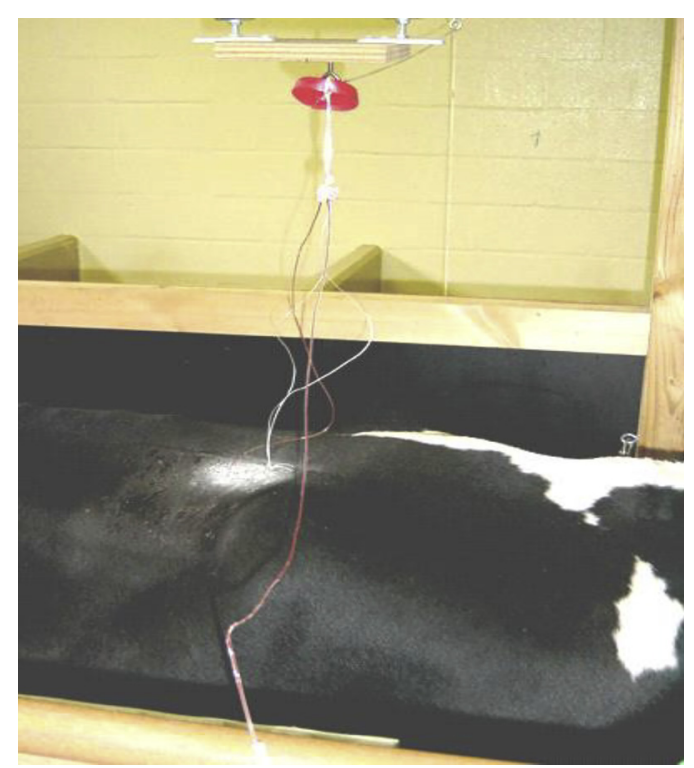

Fig. 14. The external end of the catheter was transferred through a pulley above the cow to a hood containing a small container of $50 \%$ ethanol 


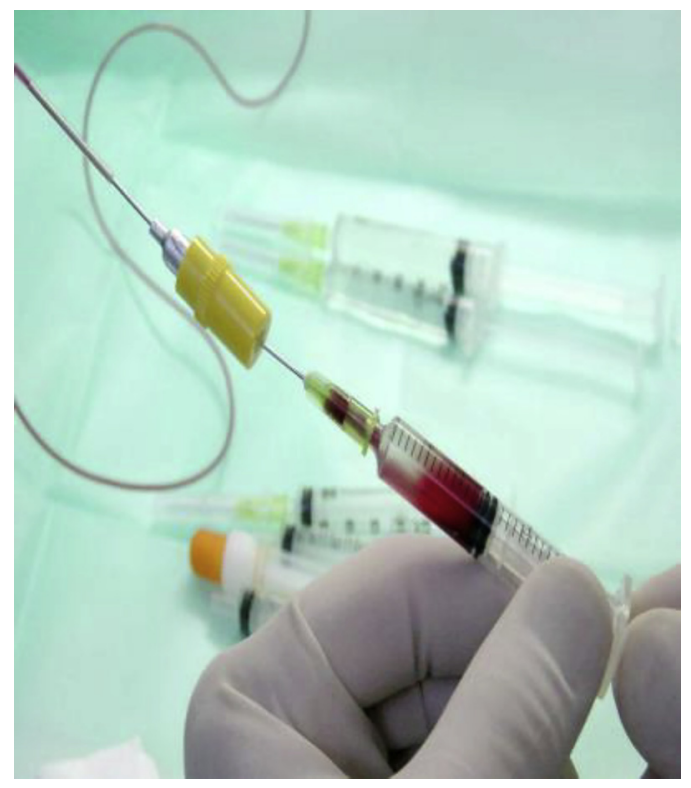

Fig. 15. Before blood sampling, heparinised saline was removed and $1 \mathrm{~mL}$ of blood was withdrawn for acid-base measurements. After sampling, heparinised saline $(200-250 \mathrm{IU} / \mathrm{mL}$ in $0.9 \%$ saline) was used again to remove the blood from the catheter

Days 281 and 285 after mating. Eleven of the remaining 14 cows (87.5\%) aborted at a mean time of $26 \pm 3$ (range: $11-52$ ) days after surgery. Later on the same blood vessels in Brahman and Charolais cows $(n=18)$ were cannulated on $220 \pm 0.4$ days of gestation and only two cows (11.1\%) were lost until $227 \pm 0.4$ days of gestation when the animals were used for an infusion treatment with deuterium oxide (Ferrell, 1991).

Adams et al. (1998) operated eight crossbred cows between 255 and 265 days of gestation and all cows recovered well after surgery, however one fetus (12.5\%) developed inutero infection at Day 14 after surgery and was dead at delivery two days later. The mean interval between operation and parturition was 13.6 (between 7 and 22) days, resulting in a mean gestational age of 277.6 (between 272 and 287) days at calving. The dorsal metatarsal artery and lateral saphenous vein were cannulated via a left paralumbar fossa laparotomy in right lateral recumbency.
Sangild et al. (2000) reported that out of 24 dairy heifer operations (the fetal anterior tibial artery and the saphenous vein as well as the umbilical artery were cannulated in a lateral position through a paramedian incision) performed between 246 and 253 days of gestation 10 fetuses were lost within 5 days after surgery $(41.7 \%)$. The duration of the operation was between 3 and $3.5 \mathrm{~h}$. Bacterial infections were associated with 6 fetal deaths because either Trueperella pyogenes, Escherichia coli, enterococci or oral streptococci were cultured from the fetal blood. The presence of maternal hyperthermia $\left(>40{ }^{\circ} \mathrm{C}\right)$ in response to surgery contributed to two fetal deaths since bacteriological examinations of the fetuses were negative. One fetus died of a surgery-induced torsion of the uterus and another one after a surgeryinduced fetal haemorrhage. Due to the experimental protocol on Days 5-6 after surgery 14 catheterised calves were delivered by Caesarean section.

Schmidt et al. (2004) reported that 7 Danish Red and Holstein-Friesian pregnant cows (the umbilical cord via a caruncle was catheterised) were operated in standing position and only one fetus was lost (14.3\%) within 2-5 days after surgery. The duration of operation was between 2 and $2.5 \mathrm{~h}$. It was concluded that a shorter total time of surgery and a less invasive operative procedure can lower the risk of infection and the stress during and after surgery.

Aoki et al. (2002) reported that 15 cows (Japanese Black, Holstein-Friesian and crosses) were operated in standing position between 239 and 262 days of gestation. The pregnant uterine horn was exposed through incision of the left paralumbar fossa and the fetal hindlimb $(n=7)$, forelimb $(n=3)$ vein or the veins of the chorion $(n=5)$ were catheterised with four different catheters. When angiographic catheters covered with spring tube were used for fetal forelimb and hindlimb veins $(n=7)$, the operators were able to withdraw blood samples from six cows during a 16-day (mean) period between 11 and 22 days after the operations. The mean duration of gestation was 280 days (between 271 and 291 days). In the remaining cow three samples could be withdrawn and calving occurred on Day 267. When using other catheters [polyvinyl chloride tube $(n=4)$, medical tube $(n=1)$ or angiographic catheter $(n$

Table 1. The data of successful catheterisations

\begin{tabular}{|c|c|c|c|c|c|c|}
\hline Cow & $\begin{array}{c}\text { Duration of } \\
\text { gestation (days) }\end{array}$ & $\begin{array}{c}\text { Duration between } \\
\text { operation and calving } \\
\text { (days) }\end{array}$ & $\begin{array}{l}\text { Period of sampling } \\
\text { (post-surgery) }\end{array}$ & $\begin{array}{l}\text { Duration of blood } \\
\text { sampling (days) }\end{array}$ & $\begin{array}{c}\text { Gender of the } \\
\text { calf }(\mathrm{M} / \mathrm{F})\end{array}$ & $\begin{array}{l}\text { Birth } \\
\text { weight } \\
(\mathrm{kg})\end{array}$ \\
\hline C6 & 259 & 27 & D4-D27 & 24 & M & 33 \\
\hline C7 & $275^{\mathrm{a}}$ & 95 & D4-D95 & 92 & M & 42 \\
\hline $\mathrm{C} 8$ & 264 & 31 & D4-D26 & 23 & F & 27 \\
\hline C9 & 274 & 39 & D4-D39 & 36 & $\mathrm{M}^{\mathrm{b}}, \mathrm{M}$ & $33^{b}-36$ \\
\hline \multirow[t]{2}{*}{$\mathrm{C} 10$} & 272 & 35 & D4-D13 & 10 & M & 38 \\
\hline & & & $\mathrm{D} 18-\mathrm{D} 34^{\mathrm{c}}$ & $17^{\mathrm{c}}$ & & \\
\hline C11 & 277 & 28 & D4-D28 & 25 & $\mathrm{~F}$ & 39 \\
\hline Mean & 270 & 42.5 & - & 35 & - & 35.4 \\
\hline
\end{tabular}

M: male, F: female.

${ }^{\text {a}}$ Predicted duration of gestation because the exact date of AI was not correctly given at purchase.

${ }^{\mathrm{b}}$ Catheterised.

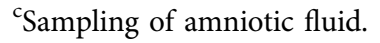


$=3)$, less than three samples could be withdrawn per animal.

In contrast, Taverne et al. (1988) reported that 10 pluriparous Dutch-Friesian pregnant cows were operated on $248 \pm 3.9$ (SEM) days of gestation and all cows recovered well after surgery. The mean interval between operation and parturition was $18.1 \pm 2.0$ days (SEM), resulting in a mean gestational age of $267 \pm 2.7$ days (SEM) at calving. In eight cases the anterior tibial artery while in two cases the saphenous vein was cannulated in dorsal position.

Hunter et al. (1977) catheterised the fetal saphenous vein towards the posterior vena cava in five pregnant Jersey cows in lateral position after opening the abdominal cavity in the left paralumbar fossa. The duration of the operation was 1$1.5 \mathrm{~h}$ and each cow gave birth to a healthy calf between 274 and 281 days of gestation (mean: 278 days).

Similarly, Wilson et al. (1977) operated six Friesian or Friesian-cross cows on $228 \pm 6$ (between 208 and 244) days of gestation and all cows recovered well after surgery. The mean interval between operation and parturition was $19.3 \pm$ 5.3 (between 11 and 27) days, resulting in a mean gestational age of $247 \pm 6$ (between 227 and 269) days at calving. Through the fetal lateral tarsal vein the fetal caudal vena cava was cannulated via a left lower flank laparotomy in lateral recumbency.

It was also mentioned that on several occasions blood samples could not be withdrawn because of blocked catheters (Taverne et al., 1988). Clotted fetal catheters were also observed on a number of occasions by Sangild et al. (2000) and also by ourselves.

In conclusion, it is very important to emphasise that a well-trained surgical team is needed for bovine fetal cannulation in order to be able to decrease the risk factors during the operations. Due to the fact that after five unsuccessful cases none of the pregnancies were lost, this skill can be reached and our technique can enable bovine fetal blood sampling for long-term endocrinological and physiological investigations before and during parturition.

\section{REFERENCES}

Adams, R., Garry, F., Holland, M. D., Hay, W. W. and Wagner, A. (1998): Cannulation technique for the late gestation bovine fetus. Theriogenology 49, 337 (Conference abstract).

Aoki, M., Kimura, K., Hirako, M., Hanafusa, Y., Ishizaki, H. and Kariya, Y. (2002): Cannulation for a bovine fetus in late gestation under regional anesthesia. J. Reprod. Dev. 48, 455460.

Comline, R. S., Hall, L. W., Lavelle, R., Nathanielsz, P. W. and Silver, M. (1974): Parturition in the cow: endocrine changes in animals with chronically implanted catheters in the foetal and maternal circulations. J. Endocrinol. 63, 451-472.
Comline, R. S., Hall, L. W., Lavelle, R. and Silver, M. (1975): The use of intravascular catheters for long-term studies on the mare and fetus. J. Reprod. Fertil. Suppl. 23, 583-588.

Comline, R. S. and Silver, M. (1970): Daily changes in foetal and maternal blood of conscious pregnant ewes, with catheters in umbilical and uterine vessels. J. Physiol. 209, 567-586.

Comline, R. S. and Silver, M. (1972): The composition of foetal and maternal blood during parturition in the ewe. J. Physiol. 222, 233-256.

Comline, R. S. and Silver, M. (1974): A comparative study of blood gas tensions, oxygen affinity and red cell 2,3 DPG concentrations in foetal and maternal blood in the mare, cow and sow. J. Physiol. 242, 805-826.

Comline, R. S. and Silver, M. (1976): Some aspects of foetal and uteroplacental metabolism in cows with indwelling umbilical and uterine vascular catheters. J. Physiol. 260, 571-586.

Ferrell, C. L. (1991): Maternal and fetal influences on uterine and conceptus development in the cow: II. Blood flow and nutrient flux. J. Anim. Sci. 69, 1954-1965.

Ferrell, C. L., Ford, S. P., Prior, R. L. and Christenson, R. K. (1983): Blood flow, steroid secretion and nutrient uptake of the gravid bovine uterus and fetus. J. Anim. Sci. 56, 656-667.

Hunter, J. T., Fairclough, R. J., Peterson, A. J. and Welch, R. A. (1977): Foetal and maternal hormonal changes preceding normal bovine parturition. Acta Endocrinol. (Copenh.) 84, 653-662.

Kersjes, A. W., Németh, F. and Rutgers, L. J. E. (1985): Atlas of Large Animal Surgery. Wetenschappelijke uitgeverij Bunge, Utrecht, The Netherlands.

Meschia, G., Cotter, J. R., Breathnach, C. S. and Barron, D. H. (1965): The hemoglobin, oxygen, carbon dioxide and hydrogen ion concentrations in the umbilical bloods of sheep and goats as sampled via indwelling plastic catheters. Q. J. Exp. Physiol. Cogn. Med. Sci. 50, 185-195.

Randall, G. C. (1977): Daily changes in the blood of conscious pigs with catheters in foetal and uterine vessels during late gestation. J. Physiol. 270, 719-731.

Sangild, P. T., Schmidt, M., Jacobsen, H., Fowden, A. L., Forhead, A., Avery, B. and Greve, T. (2000): Blood chemistry, nutrient metabolism, and organ weights in fetal and newborn calves derived from in vitro-produced bovine embryos. Biol. Reprod. 62, 1495-1504.

Schmidt, M., Sangild, P. T., Jacobsen, H. and Greve, T. (2004): A method to reduce the invasiveness of fetal catheterization in the cow. Anim. Reprod. Sci. 80, 193-200.

Taverne, M. A. M., Bevers, M. M., Van der Weyden, G. C., Dieleman, S. J. and Fontijne, P. (1988): Concentration of growth hormone, prolactin and cortisol in fetal and maternal blood and amniotic fluid during late pregnancy and parturition in cows with cannulated fetuses. Anim. Reprod. Sci. 17, 51-59.

Wilson, G. D., Hunter, J. T., Derrick, G. H., Aitken, W. M. and Kronfeld, D. S. (1977): Fetal and maternal mineral concentrations in dairy cattle during late pregnancy. J. Dairy Sci. 60, 935-941.

Open Access statement. This is an open-access article distributed under the terms of the Creative Commons Attribution 4.0 International License (https:// creativecommons.org/licenses/by/4.0/), which permits unrestricted use, distribution, and reproduction in any medium, provided the original author and source are credited, a link to the CC License is provided, and changes - if any - are indicated. (SID_1) 